\title{
Protective Effect of Curcumin on Quality Parameters of Sperm and Testicular Tissue Alterations in Alloxan-induced Diabetic Rats as Animal Model
}

\author{
Damoon Sadoughi ${ }^{1,2}$, Mohammad Amin Edalatmanesh ${ }^{2, *}$, Raheleh Rahbarian ${ }^{3}$ \\ ${ }^{1}$ Department of Biology, Faculty of Science, Fars Science and Research Branch, Islamic Azad University, Fars, Iran \\ ${ }^{2}$ Department of Biology, Faculty of Science, Shiraz Branch, Islamic Azad University, Shiraz, Iran \\ ${ }^{3}$ Department of Biology, Faculty of Sciences, Payam-e-Noor University, Tehran, Iran \\ *Corresponding author. E-mail: amin.edalatmanesh@gmail.com
}

Received date: Jan 30, 2019; Revised date: Mar 22, 2019; Accepted date: Mar 26, 2019

\section{Abstract}

$\mathrm{B}$ ACKGROUND: Type one diabetes mellitus (DM) is a multisystem disorder whose effects are observed in the reproductive system. Considering the role of curcumin in lowering blood glucose and enhancing antioxidant defense, this research aimed to determine protective effect of curcumin on quality parameters of sperm and testicular tissue alterations in diabetic rats.

METHODS: Forty male Wistar rats were randomly divided into five groups, including control (healthy rats), DM (for diabetic model), and also curcumin-treated diabetic model (DM+CUR)50, DM+CUR100 and DM+CUR150. Diabetes was induced using an intraperitoneal injection of $240 \mathrm{mg} /$ $\mathrm{kg}$ alloxan. Following completion of the test period, all rats were sacrificed, and their testes were removed to assess sperm parameters and histological evaluation. The data was analyzed with one-way ANOVA and Tukey post hoc test. The $p<0.05$ was set as the significance level.
RESULTS: Concentration, total sperm motility (TMot), progressive sperm motility (PMot), average path velocity (VAP), curvilinear velocity (VCL), straight line velocity (VSL) of sperm in DM+CUR100 and DM+CUR150 were significantly increased $(p=0.005)$ compared to the diabetic group. Mean diameter $(p=0.004)$ and thickness of the germline epithelium of testis semeniferous tubules $(p=0.005)$ in DM+CUR100 and DM+CUR150 significantly increased compared to the diabetic group.

CONCLUSION: It can be concluded that curcumin plays a protective role in testicular tissue alterations and improves sperm parameters. In this regard, curcumin could be suggested to be one of the natural antioxidants that can improve fertility in diabetic patients.

KEYWORDS: diabetes mellitus, curcumin, spermatozoa, testis, rats

Indones Biomed J. 2019; 11(3): 240-6

\section{Introduction}

Diabetes mellitus (DM) as one of the most common chronic diseases includes a group of metabolic disorders with the main characteristic of chronic hyperglycemia. Hyperglycemia is caused due to defect in insulin secretion or function or both, and it can lead to disturbances in carbohydrate and lipoprotein metabolism.(1) DM is one of the main causes of reproductive disorders characterized by testicular tissue dysfunction, pituitary gonadal axis disorder and reduced sperm quality.(2)
Many studies have indicated the link between diabetes and oxidative stress by measuring various parameters, including lipid peroxidation and DNA damage. $(3,4)$ It is specified that decline in cellular antioxidant defenses plays a crucial role in development of male infertility complications in diabetic patients.(2) Reactive oxygen species (ROS) level elevation in diabetes may decrease antioxidant enzymes activity. The excess generation of ROS and decrease in endogenous antioxidant defenses make the tissues susceptible to oxidative stress, leading to the development of diabetes complications.(5) 
Oxidative stress can be decreased by using various natural antioxidants. Recently, herbs and spices have attracted a significant attention as natural antioxidants. Curcuma longa is one of the medicinal plants that has many antioxidant compounds.(6) The pharmacological activity of Curcuma longa is related to its active ingredients, such as polyphenol. Generally, curcumin is the most abundant pungent and the main compound in Curcuma longa. $(7,8)$ Curcumin has been found to have multiple actions such as hypoglycemic and hypolipidemic properties, antiinflammatory action through inhibition of nuclear factor kappa- $\beta$, anti-cancer action through cell-cycle arrest, antioxidant action through inhibition of free radicals, suppression of lipid peroxidation, increase of antioxidant molecules in tissues and stimulation of the activity of antioxidant enzymes.(9) Ample evidence has shown that curcumin improves $\beta$-cell function and reduces insulin resistance linked to diabetes mellitus by activating antiinflammatory signaling pathways. $(10,11)$ The recent study demonstrated that curcumin with low concentrations improves sperm motility in diethylhexylphthalate (DEHP)induced damage of seminiferous tubules.(12) Computerassisted semen analysis showed that curcumin can improves sperm motility of leukocytospermia patients, against the oxidative damage induced by hydrogen peroxide.(13) Studies have indicated that curcumin increase spermatozoa with normal morphology and sperm motility in male wistar rats.(14) Another study showed that addition of curcumin during freezing resulted in positive effects on sperm motility and the number of spermatozoa after thawing.(15) In the current experiment, we investigated effects of curcumin on sperm quality parameters and testicular tissue alterations in alloxan-induced diabetic rats.

\section{Methods}

All experiments in the present experimental study were in accordance with the internationally accepted principles for care and use of laboratory animals (NIH Publication No. 8023 , revised in 1996). The ethics committee of Islamic Azad University of Shiraz approved the study protocols (IR.IAU. SHIRAZ.REC.1395.2.7800)

\section{Animals}

Wistar rats with a weight range of $180 \pm 4 \mathrm{~g}$ from the Razi Vaccine and Serum Research Institute of Mashhad were prepared. The animals were kept in standard transparent polycarbonate cages with free access to food and water in the
Animal Lab Center of Islamic Azad University of Shiraz for a total of 100 days, including 10 days of adaptation period, 60 days of inducing chronic diabetes and 30 days of testing period. Animals were kept at $22 \pm 2^{\circ} \mathrm{C}$ temperature, $35 \pm 5$ percent humidity and on a 12:12 hour light:dark cycle.

\section{Induction of Experimental Diabetes}

Alloxan monohydrate (CAS Registry No.: 2244-113, Catalogue No. A7413, Sigma-Aldrich, Munich, Germany) was used to induce diabetes in rats as a single intraperitoneal (i.p.) dose (240 mg/kg BW) dissolved in citrate buffer $(\mathrm{pH}=5.4) .60$ days after injection of alloxan monohydrate, fasting blood glucose level was measured by a glucometer (IGM-0002A, Catalogue No.: IMC00630, Infopia EasyGluco, Anyang, Korea) with a drop of tail blood to confirm chronic diabetes. Rats whose blood glucose concentration was higher than $300 \mathrm{mg} / \mathrm{dL}$ were considered diabetic and entered the next stage for treatment.(16)

\section{Experimental Design}

Forty rats were randomly divided into five eight-rat groups (each group was kept in a separate cage) including control group which treated with dimethyl sulfoxide (DMSO) (CAS Registry No.: 67-68-5, Catalogue No.: D2650, Sigma-Aldrich) as vehicle $(0.5 \mathrm{~mL}$, i.p.), DM (for control diabetic group which treated with DMSO; $0.5 \mathrm{~mL}$, i.p.), and DM+CUR50, DM+CUR100 and DM+CUR150 (for curcumin-treated diabetic model which was treated with DMSO and 0.5 mL curcumin (CAS Registry No.: 458-37-7, Catalogue No.: C1386, Sigma-Aldrich) with a concentration of 50,100 and $100 \mathrm{mg} / \mathrm{kg}$ body weight.

\section{Histomorphometrical Analysis}

In sterile conditions, an incision was made in the lower abdomen, and right and left testes were removed and placed in a physiological serum. For histological studies, testes were fixed in bouin's solution for 24 hours, and preparation stages were performed with the standard procedure, and finally they were embedded in paraffin. Six $\mu \mathrm{m}$ serial sections perpendicular to the transverse axis of testes were prepared and stained using Hematoxilin-Eosin method. To measure mean diameter semeniferous tubules and thickness of the germline epithelium, a light microscope (Olympus CX21FS1, Olympus, Tokyo, Japan) fitted with an eye piece micrometer with $100 \times$ magnification and calibrated by a stage micrometer was used. Measurements were expressed in microns. Images were taken using a digital camera (Color view XC30, Olympus) and software for image capture 
(CellSens Dimension v1.6, Olympus). Mean diameter of the seminiferous tubule was calculated across minor and major axes.(17)

\section{Computer Assisted Semen Analysis (CASA)}

Using AndroVision ${ }^{\circledR}$ CASA system (Minitube, Beijing, China) with AxioScope optics (ZEISS.A1, Hannover, Germany) and automated ScanStage (Minitube), seminal parameters were measured. Including: sperm concentration $10^{6} / \mathrm{mL}$, total sperm motility (Tmot) percentage, progressive sperm motility (PMot) percentage, average path velocity (VAP) $\mu \mathrm{m} / \mathrm{s}$, curvilinear velocity (VCL) $\mu \mathrm{m} / \mathrm{s}$, straight line velocity (VSL) $\mu \mathrm{m} / \mathrm{s}$, straightness as straight line velocity/average path velocity (STR), linearity as straight line velocity/curvilinear velocity (LIN), wobble as average path velocity/curvilinear velocity (WOB), amplitude of lateral head displacement (ALH) $\mu \mathrm{m}$, beat cross frequency (BCF) Hz.(18)

\section{Data Analysis}

The data was analyzed using IBM SPSS Statistics version 25 (IBM, New York, USA) application. By the Kolmogorov-Smirnov test, the assumption of the normal distribution of data was determined $(p>0.05)$. To compare the mean between the groups tested, one-way ANOVA and to compare paired groups Tukey's test was used. The results obtained with the relevant statistical calculations as $\mathrm{Mean} \pm \mathrm{SEM}$ were reported. The $p<0.05$ was set as the significance level.

\section{Results}

The results showed that concentration, TMot, PMot, VAP, VCL and VSL of sperm in the DM and DM+CUR50 groups significantly decreased $(p=0.002)$ compared to the control group. STR, LIN, WOB, ALH and BCF of sperm in DM and DM+CUR50 groups there was no significant difference compared to the control group $(p=0.091)$. Concentration, TMot, PMot, VAP, VCL and VSL of sperm in DM+CUR100 and DM+CUR150 groups significantly increased $(p=0.005)$ compared to the DM group. STR, LIN, WOB, ALH and BCF of sperm in DM+CUR100 and DM+CUR150 there was no significant difference compared to the DM group ( $p=0.084)$. Concentration, TMot, PMot, VAP, VCL, VSL, STR, LIN, WOB, ALH and BCF of sperm in DM+CUR50 there was no significant difference compared to the DM group ( $p=0.107$ ) (Table 1$)$.

The results of this study showed that mean diameter of the seminiferous tubule of testis in the DM and DM+CUR50

Table 1. Mean values and standard deviation obtained within the computer-assisted analysis of diabetic rat's sperm after treated with curcumin.

\begin{tabular}{|c|c|c|c|c|c|}
\hline Groups $(\mathrm{n}=8)$ & Control & DM & DM+CUR50 & DM+CUR100 & DM+CUR150 \\
\hline Conc $\left(\times 10^{6} / \mathrm{mL}\right)$ & $87.93 \pm 8.43$ & ${ }^{\mathrm{a}} 38.68 \pm 5.08$ & ${ }^{\mathrm{a}} 42.58 \pm 4.73$ & ${ }^{\mathrm{bc}} 65.22 \pm 6.30$ & ${ }^{b c} 79.60 \pm 7.41$ \\
\hline TMot (\%) & $53.17 \pm 10.14$ & ${ }^{\mathrm{a}} 22.78 \pm 4.83$ & ${ }^{\mathrm{a}} 25.11 \pm 3.40$ & ${ }^{b c} 38.00 \pm 5.71$ & ${ }^{b c} 45.30 \pm 5.54$ \\
\hline PMot (\%) & $48.09 \pm 5.40$ & ${ }^{\mathrm{a}} 24.13 \pm 5.40$ & ${ }^{\mathrm{a}} 28.61 \pm 6.70$ & $\mathrm{bc}_{37.53 \pm 4.12}$ & ${ }^{\mathrm{bc}} 40.51 \pm 6.72$ \\
\hline $\mathrm{VAP}(\mu \mathrm{m} / \mathrm{s})$ & $64.75 \pm 5.37$ & $\mathrm{a}_{32.70 \pm 7.45}$ & ${ }^{\mathrm{a}} 38.25 \pm 6.37$ & ${ }^{\mathrm{bc}} 50.61 \pm 9.17$ & ${ }^{\mathrm{bc}} 53.22 \pm 4.17$ \\
\hline $\operatorname{VCL}(\mu \mathrm{m} / \mathrm{s})$ & $115.14 \pm 12.87$ & ${ }^{\mathrm{a}} 77.23 \pm 5.07$ & ${ }^{\mathrm{a}} 79.32 \pm 4.40$ & ${ }^{\mathrm{bc}} 89.20 \pm 5.38$ & ${ }^{b c} 94.70 \pm 8.20$ \\
\hline $\operatorname{VSL}(\mu \mathrm{m} / \mathrm{s})$ & $58.60 \pm 7.38$ & a $30.14 \pm 4.17$ & $\mathrm{a}_{34.20 \pm 2.75}$ & ${ }^{b c} 43.58 \pm 6.05$ & ${ }^{\mathrm{bc}} 48.58 \pm 7.30$ \\
\hline STR & $0.90 \pm 0.18$ & $0.92 \pm 0.11$ & $0.89 \pm 0.14$ & $0.86 \pm 0.09$ & $0.91 \pm 0.11$ \\
\hline LIN & $0.50 \pm 0.11$ & $0.39 \pm 0.09$ & $0.43 \pm 0.07$ & $0.48 \pm 0.05$ & $0.51 \pm 0.06$ \\
\hline WOB & $0.56 \pm 0.09$ & $0.42 \pm 0.08$ & $0.48 \pm 0.11$ & $0.56 \pm 0.12$ & $0.56 \pm 0.14$ \\
\hline $\mathrm{ALH}(\mu \mathrm{m})$ & $4.88 \pm 0.82$ & $4.30 \pm 0.68$ & $4.92 \pm 0.37$ & $4.63 \pm 0.72$ & $4.70 \pm 0.51$ \\
\hline $\mathrm{BCF}(\mathrm{Hz})$ & $28.61 \pm 8.11$ & $30.45 \pm 5.52$ & $26.30 \pm 7.31$ & $27.14 \pm 2.90$ & $31.47 \pm 2.15$ \\
\hline
\end{tabular}

Data are expressed as mean \pm SD of eight replicates. Showing results significantly different from control groups (a: $p<0.05$ ); Showing results significantly different from DM (b: $p<0.05)$; Showing results significantly different from DM+CUR50 (c: $p<0.05)$. DM: diabetic model; DM+CUR: curcumin-treated diabetic model; Conc: sperm concentration; TMot: total sperm motility; PMot: progressive sperm motility; VAP: average path velocity; VCL: curvilinear velocity; VSL: straight line velocity; STR: straightness as straight line velocity/ average path velocity; LIN: linearity as straight line velocity/curvilinear velocity; WOB: wobble as average path velocity/curvilinear velocity; ALH: amplitude of lateral head displacement; BCF: beat cross frequency. 
groups significantly decreased $(p=0.008)$ compared to the control group. Mean diameter of the seminiferous tubule of testis in DM+CUR100 and DM+CUR150 groups significantly increased $(p=0.004)$ compared to the DM. Mean diameter of the seminiferous tubule of testis in DM+CUR50 there was no significant difference compared to DM group ( $p=0.091)$ (Figure 1).

The findings of present study showed that the thickness of germline epithelium of testis semeniferous tubules in DM and DM+CUR50 groups significantly decreased $(p=0.001)$ compared to the control group. The thickness of germline epithelium of testis semeniferous tubules in DM+CUR100 and DM+CUR150 groups significantly increased $(p=0.005)$ compared to DM group. The thickness of germline epithelium of testis semeniferous tubules in DM+CUR50 there was no significant difference compared to DM group $(p=0.084)$ (Figure 2).

Normal tissue structure of seminiferous tubules was observed in the control group. In DM group atrophic seminiferous tubules were increased $(p<0.05)$. In $\mathrm{DM}+\mathrm{CUR} 100$ and DM+CUR150 groups, atrophic tubules significantly decreased and the number of normal tubules significantly increased $(p<0.05)$ (Figure 3$)$.

\section{Discussion}

In the present research, alloxan monohydrate was used to induce diabetes in rats. Research has shown that alloxan causes extensive $\beta$-cell destruction in the pancreas in 18 to 24

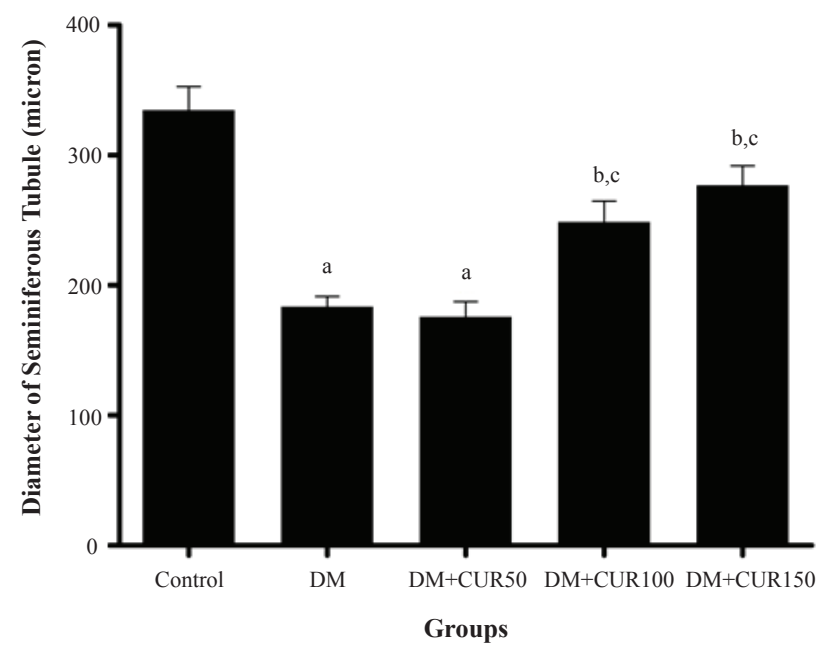

Figure 1. Mean diameter of the seminiferous tubule of testis in diabetic rats after treated with curcumin. Data are expressed as mean $\pm \mathrm{SD}$ of eight replicates. Showing results significantly different from control groups (a: $p<0.05$ ); Showing results significantly different from DM (b: $p<0.05$ ); Showing results significantly different from DM+CUR50 (c: $p<0.05$ ).

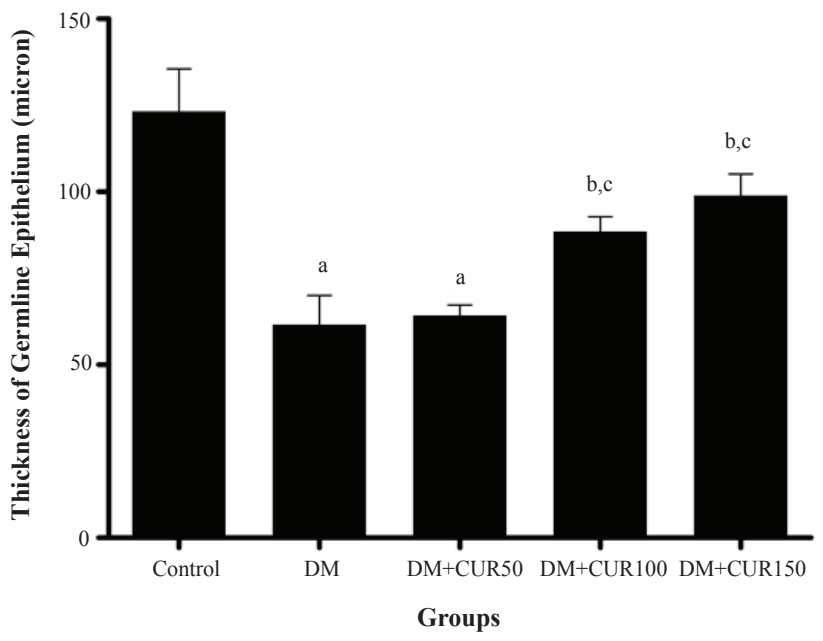

Figure 2. The thickness of germline epithelium of testis semeniferous tubules in diabetic rats after treated with curcumin. Data are expressed as mean \pm SD of eight replicates. Showing results significantly different from control groups (a: $p<0.05$ ); Showing results significantly different from DM (b: $p<0.05$ ); Showing results significantly different from DM+CUR50 (c: $p<0.05)$.

hours after injection, leading to hyperglycemia. The reason for selective toxicity of alloxan is its structural resemblance to glucose, and its effective mechanism is producing free radicals.(19) Increased blood glucose level during diabetes is similar to previous investigations as a result of the marked degeneration of pancreatic cells by alloxan monohydrate, leading to decreased insulin secreting.(20)

The results of the present study showed that tissue structure of testis in the diabetic rats significantly changed compared to the control group. Moreover, concentration, TMot, PMot, VAP, VCL and VSL of sperm in the diabetic rats significantly decreased compared to the control group. Researchers reported that diabetes could adversely affect activity of pituitary-gonadal axis. They also reported that in diabetes caused by an insulin deficiency, oxidative stress affected germ cell apoptosis in testicular tissue of adult diabetic rats.(21) Previous reports showed that diabetes adversely affects hypophysis-gonadal hormone axis, causing a reduction in the secretion of gonadotropins and testosterone, which eventually leads to the impairment of spermatogenesis and sperm motility defect.(22) Studies have indicated that testicular weight, number of male sex cells, sertoli and leydig cells decreased in diabetic groups. Furthermore, the seminiferous tubule diameter, the seminiferous epithelium height and fertility rates decreased in diabetic groups. Also, diabetes can increase the risk of seminiferous tubule degeneration.(2) It has been reported that quality parameters of sperm, number of sertoli cells and 

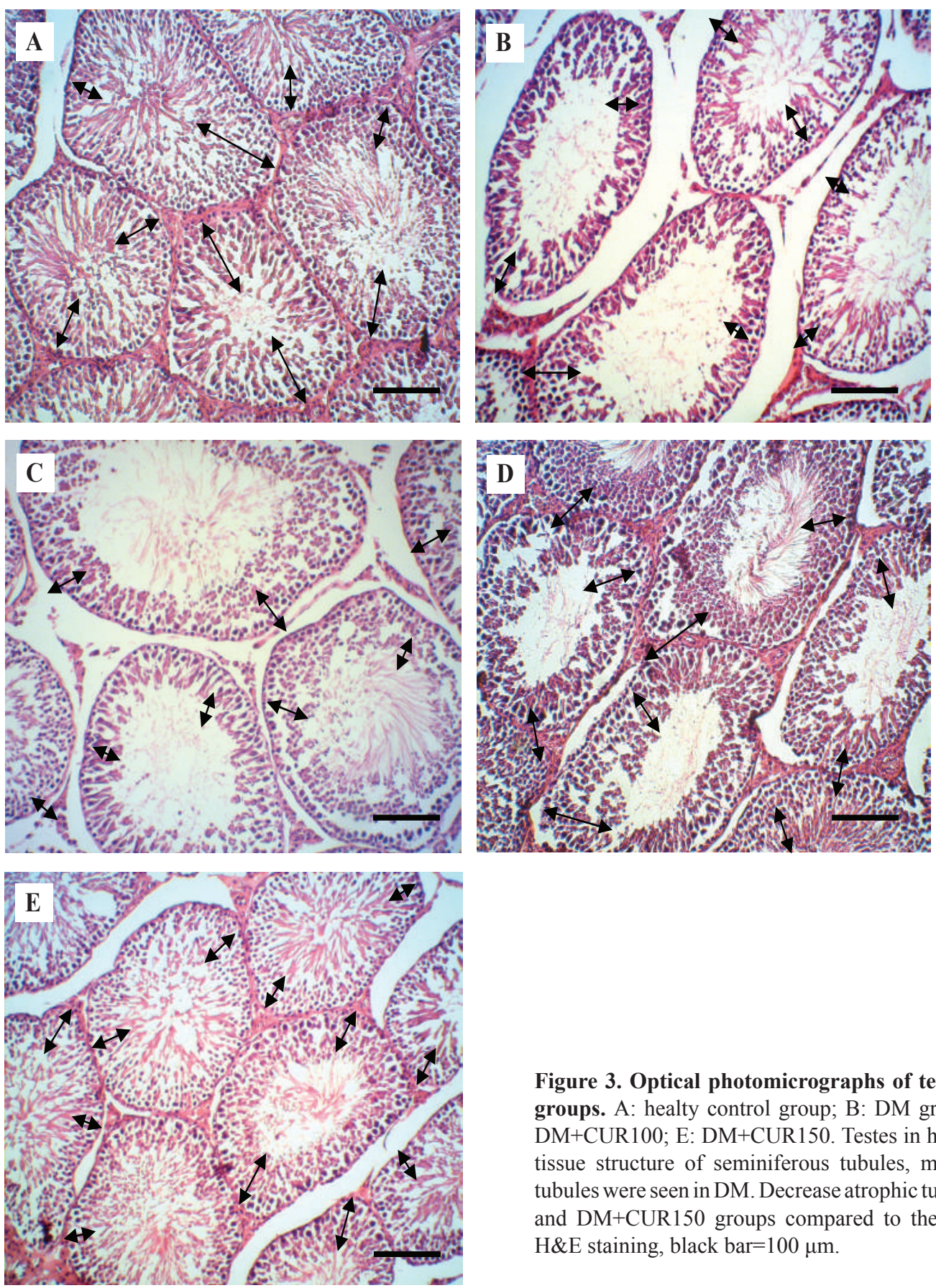

Figure 3. Optical photomicrographs of testes tissue in the experimental groups. A: healty control group; B: DM group; C: DM+CUR50 group; D: DM+CUR100; E: DM+CUR150. Testes in healthy control group had normal tissue structure of seminiferous tubules, meanwhile atrophic seminiferous tubules were seen in DM. Decrease atrophic tubules were seen in DM+CUR100 and DM+CUR150 groups compared to the DM and DM+CUR50 groups. $\mathrm{H} \& \mathrm{E}$ staining, black bar $=100 \mu \mathrm{m}$.

testicular weight significantly decreased in diabetic rats. (2) Furthermore, decreasing diameter of the seminiferous tubule and thickness of tubular epithelial were shown in diabetic rat testes.(23) Decrease in spermatogenic cells and reduction in the diameter of seminiferous tubes are histopathological indicators of spermatogenesis failure in diabetic rats.(24) Other studies also showed the important role of diabetes mellitus in reducing testicular weight.(2) More recent studies have shown that, diabetes obviously affects spermatogenesis and significantly reduces the semen quality. In addition, it has been demonstrated that diabetes causes testicular damage with significant apoptosis of testicular tissue in rats. $(25,26)$

The present study findings showed that thickness of germline epithelium and mean diameter of the seminiferous tubule of testis in diabetic groups treated with 100 and $150 \mathrm{mg} / \mathrm{kg}$ of curcumin compared to the diabetic group significantly increased. Furthermore, concentration, TMot, PMot, VAP, VCL and VSL of sperm in diabetic groups treated with 100 and $150 \mathrm{mg} / \mathrm{kg}$ of curcumin significantly 
increased compared to the diabetic group. In many related studies, hypoglycemic effect of curcumin was reported. In accordance with previous reports, it was observed that oral administration of curcumin was effective in reducing blood glucose levels.(27) The previous study showed that curcumin effectively reduced the blood glucose levels by increase pancreatic islets viability and basal insulin secretion.(28) In another study reported that administration of curcumin by regeneration pancreatic islet, significantly reversed hyperglycemia.(29) One recent study demonstrated that curcumin was able to diminish testicles molecule free radicals in an streptozotocin (STZ)-induced diabetic mouse model. Furthermore, anti-diabetic agent of curcumin was reported.(30) Furthermore, researchers have realized that treating rats with curcumin by increase the activity of leydig cells and synthesis of steroid hormones, increases spermatogenesis.(31) Ample evidence also indicates that curcumin has protective effects on sperm parameters. In addition, ithas beendemonstrated thatcurcuminhas protective effects against cisplatin-induced testicular disorders in rats. Moreover, it has been reported that quality parameters of sperm significantly increase in curcumin treated groups compared to cisplatin treated groups.(32) According to the previous study, curcumin is a potential therapeutic agent for reduced testicular apoptosis by decrease in the $\mathrm{Bax} / \mathrm{Bcl}-2$ ratio and also inhibited oxidative stress levels by decrease lipid peroxidation and regulation of antioxidant enzyme activities.(33) Another study indicated that curcumin (0.5 and $10 \mu \mathrm{M}$ ) by decreasing oxidative stress, improve boar sperm characteristics such as motility, viability and plasma membrane integrity.(34) Previous study demonstrated that curcumin by reduction in the malondialdehyde content and increase in superoxide dismutase activity and glutathione peroxidase levels improved pathological alterations in the testis and prevented cyclophosphamide-induced reduction in reproductive organs weights, sperm count, motility and viability.(35) It has been previously reported that curcumin had protective effects on mouse sperm motility in vitro and its ability to diminish the decrease in sperm motility in vivo on damage of testicular seminiferous tubules.(13) The research has shown that sperm viability and motility were enhanced by curcumin in roosters.(36) In another study showed that curcumin has protective effects on bull sperms exposed to oxidative stress.(37) A previous study demonstrated that treatment diabetic rats with curcumin ameliorate testicular damage by reinforcement of antioxidant defense system. (38) Scientists in another study have shown that treatment with curcumin increase sperm count ameliorates viability and improves the morphological characteristics of sperm morphology after the freeze-thawing process.(15) In another study also indicated that curcumin by antioxidant properties improved testicular histology, increased sperm count, increased testosterone level, decreased lipid peroxidation and increased antioxidant enzymes activities in rats subjected to potassium dichromate.(39) The results of this study demonstrated that the curcumin had beneficial effects on reducing pathological disorders and improving sperm quality parameters. Our findings provide confirmatory evidence for the protective role of curcumin in fertility disorders in diabetic patients. Finally, it should be noted that one of the most important limitations of the present study was lack of oxidative DNA damage analysis and lack of molecular studies to find the effects of curcumin on testicular function and sperm characteristics in diabetic rats. Future research should address molecular mechanisms underlying the protective effects of curcumin on rat testicles and sperm.

\section{Conclusion}

Curcumin treatment showed dose-related improvement in sperm quality parameters and testicular tissue alterations in diabetic rat testes. In conclusion, it is observed that curcumin reduce testicular damage and improvement in sperm quality parameters and betterment the sperm motility characteristics in type 1 diabetic rats. It is suggested that more studies be conducted on the effect of curcumin to reduce infertility disorders and testicular damage in patients with diabetes type 1 .

\section{Acknowledgments}

This study elicited from the Ph.D. thesis of Mr. Damoon Sadoughi who studied in Islamic Azad university of Shiraz. This study was supported by Biology Department of Fars Science and Research Branch and Shiraz Branch, Islamic Azad University, Iran.

This project was sponsored by Islamic Azad University of Shiraz, Iran.

\section{References}

1. Zendjabil M. Biological diagnosis of diabetes mellitus. Curr Res Transl Med. 2016: 64: 49-52.

2. Gaunay G, Nagler HM, Stember DS. Reproductive sequelae of diabetes in male patients. Endocrinol Metab Clin North Am. 2013; 42: 899-914. 
3. Rochette L, Zeller M, Cottin Y, Vergely C. Diabetes, oxidative stress and therapeutic strategies. Biochim Biophys Acta. 2014; 1840: 2709-29.

4. Asmat U, Abad K, Ismail K. Diabetes mellitus and oxidative stress-A concise review. Saudi Pharm J. 2016; 24: 547-53.

5. Lushchak VI. Free radicals, reactive oxygen species, oxidative stress and its classification. Chem Biol Interact. 2014; 224: 164-75.

6. Bjorklund $\mathrm{G}$, Chirumbolo $\mathrm{S}$. Role of oxidative stress and antioxidants in daily nutrition and human health. Nutrition. 2017; 33: 311-21.

7. Sunagawa Y, Katanasaka Y, Hasegawa K, Morimoto T. Clinical applications of curcumin. Pharma Nutrition. 2015; 3: 131-5.

8. Salehi B, Stojanović-Radić Z, Matejić J, Sharifi-Rad M, Anil Kumar NV, Martins N, et al. The therapeutic potential of curcumin: A review of clinical trials. Eur J Med Chem. 2019; 163: 527-45.

9. Soetikno V, Suzuki K, Veeraveedu PT, Arumugam S, Lakshmanan $\mathrm{AP}$, Sone $\mathrm{H}$, et al. Molecular understanding of curcumin in diabetic nephropathy. Drug Discov Today. 2013; 18: 756-63.

10. Rivera-Mancía S, Trujillo J, Chaverri JP. Utility of curcumin for the treatment of diabetes mellitus: Evidence from preclinical and clinical studies. J Nutr Intermed Metab. 2018; 14: 29-41.

11. Maithilikarpagaselvi N, Sridhar MG, Swaminathan RP, Zachariah B. Curcumin prevents inflammatory response, oxidative stress and insulin resistance in high fructose fed male Wistar rats: Potential role of serine kinases. Chem Biol Interact. 2016; 244: 187-94.

12. Głombik K, Basta-Kaim A, Sikora-Polaczek M, Kubera M, Starowicz G, Styrna J. Curcumin influences semen quality parameters and reverses the di(2-ethylhexyl)phthalate (DEHP)-induced testicular damage in mice. Pharmacol Rep. 2014; 66: 782-7.

13. Zhang L, Diao RY, Duan YG, Yi TH, Cai ZM. In vitro antioxidant effect of curcumin on human sperm quality in leucocytospermia. Andrologia. 2017; 49: 1-6. doi: 10.1111/and.12760.

14. Iranloye B, Oghochukwu U. Fertility effects of Curcumin-a kitchen Spice on Male Wistar Rat. Endocrine Abstracts. 2016; 44: 215. doi: 10.1530/endoabs.44.P215.

15. Soleimanzadeh A, Saberivand A. Effect of curcumin on rat sperm morphology after the freeze-thawing process. Vet Res Forum 2013; 4: $185-9$.

16. Radenković M, Stojanović M, Prostran M. Experimental diabetes induced by alloxan and streptozotocin: The current state of the art. J Pharmacol Toxicol Methods. 2016; 78: 13-31.

17. Koroglu P, Senturk GE, Yucel D, Ozakpinar OB, Uras F, Arbak S. The effect of exogenous oxytocin on streptozotocin (STZ)-induced diabetic adult rat testes. Peptides. 2015; 63: 47-54.

18. Ibănescu I, Leiding C, Ciornei ŞG, Roşca P, Sfartz I, Drugociu D. Differences in CASA output according to the chamber type when analyzing frozen-thawed bull sperm. Anim Reprod Sci. 2016; 166: 72-9.

19. Ezejiofor AN, Orish CN, Orisakwe OE. Cytological and biochemical studies during the progression of alloxan-induced diabetes and possible protection of an aqueous leaf extract of Costus afer. Chin J Nat Med. 2014; 12: 745-52.

20. Song I, Patel O, Himpe E, Muller CJF, Bouwens L. Beta cell mass restoration in alloxan-diabetic mice treated with EGF and gastrin. PLoS One. 2015; 10: e0140148. doi: 10.1371/journal. pone. 0140148 .

21. Shoorei H, Khaki A, Khaki AA, Hemmati AA, Moghimian M, Shokoohi M. The ameliorative effect of carvacrol on oxidative stress and germ cell apoptosis in testicular tissue of adult diabetic rats. Biomed Pharmacother. 2018; 111: 568-78.

22. Bhattacharya SM, Ghosh M, Nandi N. Diabetes mellitus and abnormalities in semen analysis. J Obstet Gynaecol Res. 2014; 40: $167-71$.
23. Roy VK, Chenkual L, Gurusubramanian G. Protection of testis through antioxidant action of Mallotus roxburghianus in alloxaninduced diabetic rat model. J Ethnopharmacol. 2015; 176: 26880.

24. Kianifard D, Sadrkhanlou R, Hasanzadeh S. The histological, histomorphometrical and histochemical changes of testicular tissue in the metformin treated and untreated streptozotocin-induced adult diabetic rats. Vet Res Forum. 2011; 2: 13-24.

25. Kanter M, Aktas C, Erboga M. Curcumin attenuates testicular damage, apoptotic germ cell death, and oxidative stress in streptozotocininduced diabetic rats. Mol Nutr Food Res. 2013; 57: 1578-85.

26. Condorelli RA, Vignera SL, Mongiò̀ LM, Alamo A, Calogero AE. Diabetes mellitus and infertility: different pathophysiological effects in type 1 and type 2 on sperm function. Front Endocrinol. 2018; 9: 1-9. doi: 10.3389/fendo.2018.00268.

27. Ghosh S, Banerjee S, Sil PC. The beneficial role of curcumin on inflammation, diabetes and neurodegenerative disease: a recent update. Food Chem Toxicol. 2015; 83: 111-24.

28. Zhang DW, Fu M, Gao SH, Liu JL. Curcumin and diabetes: a systematic review. Evid Based Complement Alternat Med. 2013; 2013: 636053. doi: 10.1155/2013/636053.

29. El-Azab MF, Attia FM, El-Mowafy AM. Novel role of curcumin combined with bone marrow transplantation in reversing experimental diabetes: Effects on pancreatic islet regeneration, oxidative stress, and inflammatory cytokines. Eur J Pharmacol. 2011; 658: 41-8.

30. Rivera-Mancía S, Lozada-García MC, Pedraza-Chaverri J. Experimental evidence for curcumin and its analogs for management of diabetes mellitus and its associated complications. Eur J Pharmacol. 2015; 756: 30-7.

31. Murphy CJ, Tang H, Van Kirk EA, Shen Y, Murdoch WJ. Reproductive effects of a pegylated curcumin. Reprod Toxicol. 2012; 34: 120-4.

32. Elballat SE. Protective effect of curcumin and vitamin $C$ each alone and in combination on cisplatin-induced sperm abnormalities in male albino rats. JOBAZ. 2016; 76: 52-9.

33. Zha W, Bai Y, Xu L, Liu Y, Yang Z, Gao H, et al. Curcumin attenuates testicular injury in rats with streptozotocin-induced diabetes. Biomed Res Int. 2018; 2018: 7468019. doi: 10.1155/2018/7468019.

34. Lee A, Lee S, Lee S, Yang B. Effects of curcumin on sperm motility, viability, mitochondrial activity and plasma membrane integrity in boar semen. Biomed Sci Letters. 2017; 23: 406-10.

35. Lu WP, Mei XT, Wang Y, Zheng YP, Xue YF, Xu DH. Zn (II)curcumin protects against oxidative stress, deleterious changes in sperm parameters and histological alterations in a male mouse model of cyclophosphamide-induced reproductive damage. Environ Toxicol Pharmacol. 2015; 39: 515-24.

36. Yan W, Kanno C, Oshima E, Kuzuma Y, Kim SW, Bai H. Enhancement of sperm motility and viability by turmeric by-product dietary supplementation in roosters. Anim Reprod Sci. 2017; 185: 195-204.

37. Tvrdá E, Tušimová E, Kováčik A, Paál D, Greifová H, Abdramanov $\mathrm{A}$, et al. Curcumin has protective and antioxidant properties on bull spermatozoa subjected to induced oxidative stress. Anim Reprod Sci. 2016; 172: 10-20.

38. Rashid K, Sil PC. Curcumin ameliorates testicular damage in diabetic rats by suppressing cellular stress-mediated mitochondria and endoplasmic reticulum-dependent apoptotic death. Biochim Biophys Acta. 2015; 1852: 70-82.

39. Chandra AK, Chatterjee A, Ghosh R, Sarkar M. Effect of curcumin on chromium-induced oxidative damage in male reproductive system. Environ Toxicol Pharmacol. 2007; 24: 160-6. 